\title{
APUNTES ETOLÓGICOS: LA INTERESANTE VIDA ANIMAL
}

\author{
ETHOLOGICAL NOTES: THE INTERESTING ANIMAL LIFE
}

\author{
Manuel Arboccó de los Heros
}

\section{RESUMEN}

El comportamiento de los animales ha cautivado el interés del hombre. Una de las causas principales de esto es, probablemente, la adecuación que el animal muestra, tan a menudo, en sus actos; su parecido a nosotros; o como aprenden ciertas cosas. Por otra parte se ha buscado conocer más a los animales para también tratar de extrapolar algo de lo hallado al campo de las personas y así conocer más la Psicología individual y el comportamiento colectivo. En el siguiente artículo detallaremos una serie de singularidades en los animales, noticiaremos de variadas características de su comportamiento, señalaremos la relación entre el instinto, la herencia y el aprendizaje y veremos si lo hallado guarda relación con el comportamiento humano.

\section{Palabras Clave}

Zoología, Etología, innato, adaptación, supervivencia, jerarquía social, aprendizaje, conducta animal

\section{ABSTRACT}

The behavior of animals has always captured the interest of man. One of the main causes of this is probably the adaptation that animals show, so often, in their acts; their similarities to us; or how they learn certain things. On the other hand, there has been an investigation to learn more about animals to also try to extrapolate part of the findings tohumans; and thus, to learn more about the Individual psychology and collective behavior. In this paper, we will single out a number of peculiarities about animals, mention several characteristics of their behavior, point out the relationship between instinct, heritage and learning, and we will see if the findings have any relationship with human behavior.

\section{Keywords}

Zoology, ethology, innate, adaptation, survival, social hierarchy, learning, animal behavior

\section{INTRODUCCIÓN}

El comportamiento de los animales siempre ha cautivado el interés del hombre. La rama de la Zoología que estudia las conexiones determinantes del comportamiento de los animales recibe el nombre de Etología.
En condiciones normales, el comportamiento de los animales cumple una función útil para la perpetuación del individuo y de la especie (Arboccó, 2015a). Cuando el hombre actúa en forma adecuada, ello se debe, a su inteligencia o capacidad para pensar. Podemos imaginarnos las acciones, podemos prever las

Psicólogo. Psicoterapeuta. Docente de la Universidad Femenina del Sagrado Corazón. Correo: manoloarbocco@gmail.com 
consecuencias de cada una, y en base a esto, elegir la alternativa que calculamos dará los resultados más favorables. Es errado suponer que el proceder de los animales se basa en algo semejante, - aún cuando desde tiempos remotos se ha dotado al animal, en cuentos y fábulas, de capacidad de pensamiento y caracteres psicológicos netamente humanos-.

La investigación moderna ha llegado a la conclusión de que el animal no es consciente o no totalmente - al menos en algunas especiesde sus actos y de que no siempre comprende la finalidad de los actos que ejecuta. Sin embargo, no todos los animales son iguales ni su desarrollo cerebral es igual, además, no podemos negar que mucho se ha hablado de la "inteligencia animal" que les permite superar los problemas $e$ inconvenientes que se presentan en su medio. Por ejemplo, los delfines no solo son capaces de aprender lo que las personas les enseñen, sino que incluso se adiestran unos a otros. Así, los delfines en cautiverio les enseñan a otros lo aprendido durante su entrenamiento. También se ha visto que los elefantes reconocen manchas colocadas en su cabeza al verse frente a un espejo; de la misma forma, se ha experimentado con orangutanes la acción de ayudar cuando un compañero o un humano tiene alguna dificultad que requiere el apoyo de otros.

En el siguiente artículo se revisan ciertos puntos que consideramos por demás interesantes: realizaremos un breve e imaginario viaje al pasado para conocer la historia de la Etología, sus precursores, así como a los científicos que consolidaron esa área de investigación. Luego, aborda los dos enfoques clásicos en el estudio del comportamiento animal: el conductista y el innatista. También se revisan los cuatro mecanismos básicos con los que la programación genética contribuye directamente a la supervivencia y adaptación de los animales. Con ese fin, se presenta una revisión de algunos textos importantes sobre el comportamiento animal. Finalmente, se trata la relación entre el instinto, la herencia y el aprendizaje.

Para iniciar esta lectura, se plantea una primera pregunta al lector: ¿Somos tan distintos de los animales o nos parecemos a ellos más allá de los parámetros consensuales? Luego de la lectura del presente artículo, cada uno llegará a sus propias conclusiones.

\section{La Etología}

"El hombre es una cuerda que se tiende entre el animal y el superhombre: una cuerda sobre un abismo" -Friedrich Nietzsche

Etología, psicología animal, ciencia del comportamiento de los animales son expresiones sinónimas para designar la disciplina que estudia el conjunto de las conductas innatas o adquiridas por las cuales un animal supera y resuelve las dificultades y problemas que le ofrece su entorno físico y biológico para vivir, sobrevivir y reproducirse.

La RAE (2014) en el diccionario oficial define Etología como parte de la biología que estudia el comportamiento de los animales, aunque esa es la segunda acepción. En la primera señala estudio científico del carácter y modos de comportamiento del hombre.

También se considera a la Etología como la rama de la Psicología animal que estudia el comportamiento de los animales en su medio natural o en condiciones muy parecidas a las de ese medio. En consecuencia, los estudios etológicos tienen como base el diseño de un repertorio de conductas observables en todas las situaciones funcionales posibles. Esto permite investigar la relación entre el ambiente, las condiciones internas del organismo (bioquímicas, fisiológicas) y su influencia en los comportamientos de los animales que contribuyen a la supervivencia y conservación de la especie.

\section{UN POCO DE HISTORIA Y PRECURSORES DE LA ETOLOGÍA}

La importancia, tal vez mayor, entre estos precursores de la etología moderna la tuvo Jakob von Uexküll, quien, en 1909, publicó su famoso trabajo "Mundo exterior e interior de los animales" donde estudió cuidadosamente 
el comportamiento del animal en su medio ambiente. Hizo notar, de modo muy especial que cada animal solamente reacciona a ciertos estímulos que desencadenan comportamientos definidos, como son la búsqueda de alimento o el apareamiento, mientras que otras cualidades que nosotros los hombres vemos en nuestro medio, sencillamente no existen para él.

Dos investigadores que, por el contrario, se interesaron en alto grado por las cuestiones del origen filogenético del esquema de comportamiento fueron el americano Charles O. Whitman y el alemán Oskar Heinroth. Whitman trabajó con diferentes especies de palomas, y su importante obra se publicó después de su muerte, en 1899. Heinroth, director del Jardín Zoológico de Berlín, publicó - principalmente durante el periodo 19101930 - una serie de trabajos que versaban sobre el comportamiento de las aves, en especial de los palmípedos. Estos dos investigadores trabajaron también en anatomía comparada y crearon un tipo de morfología comparada de esquemas de movimientos que más tarde llego a tener un papel preponderante dentro de la Etología.

Sin embargo, quien dio a conocer los trabajos de investigadores anteriores $y$ vino a destacarse como creador de la rama científica que llamo Etología fue el austriaco Konrad Lorenz (1903-1989). Cerca de su casa de Altenberg, Lorenz mantenía una gran cantidad de aves, entre otras, cuervos, grajos, gansos, garzas y muchas especies

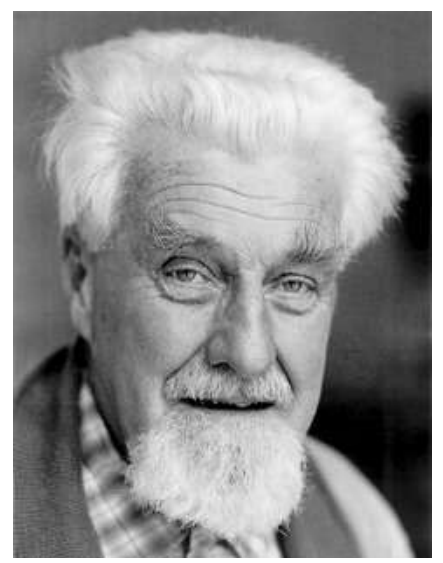

Figura 1: Konrad Lorenz, imagen tomada de: http:/www.nndb.com/people/757/000091484/ konrad-lorenz-1-sized.jpg diferentes de patos. A esas aves no se las tenía encerradas en jaulas, sino que se les permitía volar libremente, y las observó con tanto esmero que prácticamente vivía junto a ellas. Lorenz comprobó que el comportamiento del animal seguía reglas determinadas, y después de llevar a cabo durante muchos años asiduas observaciones, acumulando una rica experiencia, le fue posible resumir estos principios básicos en un sistema que podía explicar muchos de los aspectos, antes misteriosos, en lo que se refiere a los llamados instintos. Después de publicar algunos trabajos de introducción, especialmente sobre el comportamiento social de los cuervos, Lorenz presentó sus teorías en el trabajo El compañero en el mundo de las aves. Esta obra se publicó en 1935, y por ese motivo puede considerarse ese año como el que marca el nacimiento de la Etología (Fabricius, 1971).

En su libro La literatura psicológica del siglo XX, el psicólogo Ramón León dedica unas páginas a Lorenz e invita a conocer más a ese autor y a la lectura de la obra de Tascher y Foeger (2003) Konrad Lorenz: Biografia. León señala que se trata de una biografía detenida, seria, muy bien trabajada, que se ha beneficiado del acceso que han tenido los autores a material que hasta ahora no había sido explotado (León, 2010, p. 443). Excede a este artículo detenernos en la biografía de Lorenz, por esa razón, sugerimos a los interesados la lectura del famoso texto de Alec Nisbett titulado Lorenz (Nisbett, 1986).

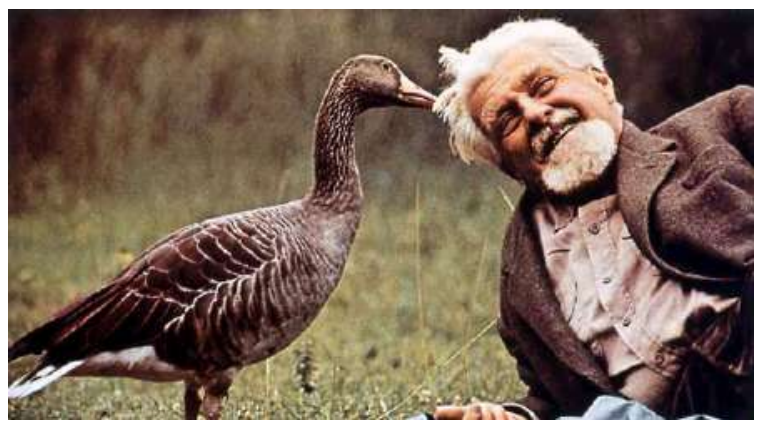

Figura 2: Graciosa toma de Lorenz, imagen extraída de: http://www.famouspsychologists. org/psychologists/konrad-lorenz.jpg 
Según Eric Fabricius, en su texto La conducta de los animales, fue principalmente el holandés Nikolaas Tinbergen (19071988) quien desarrolló y completó la técnica experimental dentro de la Etología. Tinbergen, profesor de Zoología Experimental de la Universidad de Leiden, había empezado a estudiar, independientemente de Lorenz, el comportamiento instintivo de insectos, peces, anfibios y aves. Ya desde el inicio de sus estudios, estableció contacto y una estrecha colaboración con Lorenz.

Esas primeras investigaciones despertaron gran interés entre los zoólogos de todo el mundo, y Tinbergen fue llamado a la Universidad de Oxford para organizar allí la enseñanza e investigación de la etología según los mismos principios que en Leiden. Los estudios de Tinbergen han contribuido, sobre todo, a hacer de la Etología una disciplina de rápido crecimiento como lo es hoy día, dentro de la Zoología moderna (Fabricius, 1971).

En este punto dice Denegri, "Niko Timbergen, científico de renombre mundial, ha dicho que el hombre es un asesino desorganizado, queriendo significar con esto que el hombre carece de las barreras naturales instintivas que impiden al animal matar a sus congéneres.

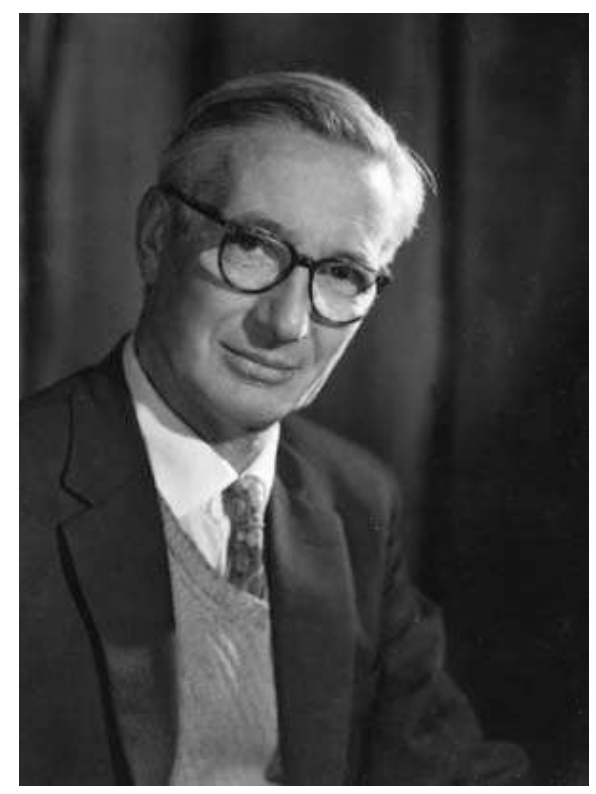

Figura 3: Nikolaas Tinbergen. Imagen tomada de: http://www.oxforddnb.com/images/articleimgs/40/40022_1_300px.jpg
Carencia que lo obliga a la creación de disuasivos -normas, leyes, preceptos y mandamientos-, que no tienen por cierto la eficacia de los frenos $e$ inhibiciones que dio natura al resto de animales" (Denegri, 2012 , p. 57). Interesante apreciación la de Timbergen. Y también la de Denegri cuando menciona "la agresividad, cuando no es destructiva ni violenta, es biológicamente útil. Si no fuésemos agresivos, entonces ya nos habríamos extinguido como especie. Ocurre, sin embargo, que el homo sápiens ha llegado a ser homo brutalis. La suya es, por tanto, como diría Fromm, agresividad maligna y necrófila, despiadada y brutal" (Denegri, 2012, p. 64).

Un tercer representante ilustre fue Karl von Frisch (1886-1982), zoólogo austriaco galardonado también con el Premio Nobel (junto a los dos anteriores), cuyos trabajos pioneros sobre la percepción química y visual de los peces y las abejas le llevaron a descubrir el modo en que las abejas melíferas se orientan y comunican. Nacido en Viena el 20 de noviembre de 1886, se doctoró en 1910 por la Universidad de Munich.

En sus primeras investigaciones, von Frisch demostró que los peces, aunque no son capaces de ver los colores, no solo pueden diferenciar muchos de ellos sino que también son muy sensibles a los sonidos. Tras comenzar sus estudios sobre las abejas melíferas a partir de 1919, descubrió que su sentido del olfato era muy parecido al de los humanos y que podían distinguir todos los colores de las flores excepto el rojo.

Después de la II Guerra Mundial, cuando regresó de la Universidad de Graz (Austria), a la de Munich (Alemania), descubrió que las abejas, gracias a su percepción de la luz polarizada, podían servirse del sol como brújula, y que incluso en días cubiertos no perdían el sentido de la orientación. Utilizando abejas marcadas, demostró que, al regresar a la colmena, una abeja realizaba una danza circular si había encontrado una fuente de alimentos a cierta distancia; si la comida se hallaba a una distancia mayor, la danza sería oscilante. 
En 1958 se retiró de la Universidad de Munich, y en 1973 compartió el Premio Nobel de Fisiología y Medicina con el holandés Nikolaas Tinbergen y con el austriaco Konrad Lorenz, ambos nominados por sus estudios sobre la conducta animal.

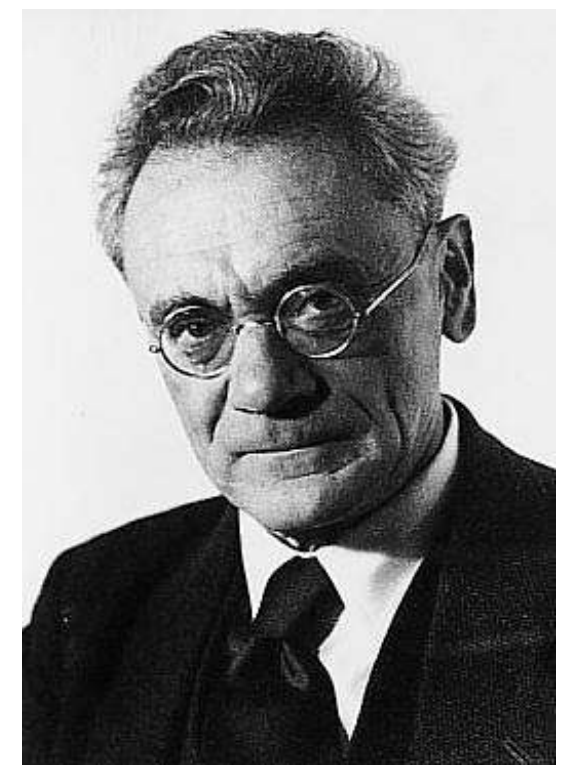

Figura 4: Karl von Frisch. Imagen tomada de: http://www.ecured.cu/images/b/b0/Karl_Von_ Frisch.jpg

La investigación y enseñanza de la Etología se imparte actualmente en la mayoría de las Universidades importantesdel mundo. En muchos lugares también se han creado institutos de investigación especiales para esta rama de la ciencia.

En un principio, la Etología encontró cierta oposición, principalmente entre algunos estudiosos americanos del comportamiento que se interesaban unilateralmente por los comportamientos aprendidos. Después que Tinbergen diera conferencias en diferentes universidades americanas y se realizaran varios simposios comunes, la colaboración entre los distintos grupos de investigadores del comportamiento se ha hecho muy intensa. Todos los investigadores modernos están ahora de acuerdo en que ni los comportamientos innatos, ni los aprendidos pueden estudiarse por separado, ya que en realidad, estos dos tipos de reacciones están tan íntimamente entrelazados que escasamente podría señalarse un esquema de comportamiento como exclusivamente innato o exclusivamente aprendido. $\mathrm{El}$ comportamiento debe estudiarse como una totalidad y, por lo tanto, con la Etología se quiere significar actualmente toda la rama de la Zoología que analiza la relación causal en que se basa el comportamiento animal (Fabricius, 1971).

El modo de actuación de los diferentes tipos de animales, es un tema que ha suscitado un enorme interés en los pensadores desde los tiempos de Platón y Aristóteles. Es particularmente interesante la habilidad de algunas criaturas simples para desarrollar tareas complejas: tejer una telaraña, construir un nido, cantar una canción, encontrar refugio o capturar a su presa; todo ello en el momento justo y con escaso o nulo aprendizaje previo. Tales comportamientos se han estudiado desde dos perspectivas bastante diferentes, de hecho casi opuestas en sus planteamientos, que exponemos a continuación: o bien los animales aprenden todo lo que hacen (enfoque conductista, haciendo hincapié en el aprendizaje), o bien saben instintivamente cómo hacerlo (enfoque etológico, que subraya el papel de la herencia).

\section{EL BEHAVIORISMO O CONDUCTISMO}

Al tiempo que se desarrollaba en Rusia una interesante escuela de psicofisiología nacida de los descubrimientos de Iván Pavlov (1849-1936), florecía en Estados Unidos un movimiento llamado a gozar de una celebridad igual: el Behaviorismo (Conductismo) con John Watson (1878-1958) a la cabeza. Este movimiento surgió a partir del propósito de algunos psicólogos norteamericanos de abandonar las vías especulativas y dotar a la psicología de métodos rigurosos. En oposición a la psicología de los "estados de conciencia" o del estudio del "subconsciente", el Behaviorismo pretendía ser mucho más objetivo y experimental. Es de esencia mecanicista en la medida en que descansa sobre el estudio del intercambio estimulorespuesta. Su filiación con Pavlov es evidente y se concentra esencialmente en el estudio de las manifestaciones externas de las reacción (Ruwet, 1975). 
Los behavioristas prestan un lugar preponderante a los comportamientos adquiridos, e incluso, desde Edward Thorndike (1874-1949) hasta B. F. Skinner (1904-1990), persiste y se refuerza la tendencia a reducir a los mecanismos del aprendizaje la explicación de todos los comportamientos: estos son controlados, y eventualmente modificados, por sus consecuencias (Ruwet, 1975).

Jean Claude Ruwet en su texto Etología, Biología del comportamiento, señala que el Behaviorismo se trata de una escuela de Psicología que se interesa por el animal tan solo como material experimental. El animal no es estudiado por sí mismo, sino que es relegado al rango de elemento intermedio o de eslabón en los programas de estudio de los mecanismos de condicionamiento y del aprendizaje. De ahí que el Behaviorismo se haya limitado al reducido registro de los animales clásicos de laboratorio (rata, ratón, gato, perro, paloma, mono rhesus), emplazados en condiciones experimentales apenas renovadas (caja de problemas varios a escoger, aparatos memorizadores, prueba del laberinto, caja de Skinner, etc.). Sin embargo, la psicología animal no puede ignorar las enseñanzas teóricas y metodológicas del Behaviorismo. Así, por ejemplo, el principio del condicionamiento operante es esencial para la comprensión de los mecanismos del aprendizaje y de la adaptación (Skinner, 1938, 1953), y sus recursos experimentales parecen indicados para favorecer el estudio cuantitativo de ciertos comportamientos y de la actividad rítmica de los animales y de los humanos (Ruwet, 1975).

Comparten esa orientación los llamados naturalistas que suelen ser agrupados bajo la denominación de "etólogos objetivistas" o "neoinstintivistas". Se trata de una escuela esencialmente europea, cuyo representante más calificado es indiscutiblemente el zoólogo austriaco Konrad Lorenz. Él es quien ha conferido a esta escuela sus títulos de nobleza científica, tanto que aún se habla con naturalidad de etología lorenziana o análisis lorenziano del comportamiento.

Pocos pueden hoy discutir que los etólogos son quienes más han contribuido a la
Psicología animal, ellos la han orientado hacia su verdadero objeto $y$ han devuelto su recto sentido. Con su demostración de la complementariedad entre instintos, taxias y aprendizajes, han puesto de manifiesto la vanidad de las querellas en las que se perdían las demás escuelas. Al echar unos puentes, al extender unas ramificaciones hacia las otras ciencias - Biología y Psicología-, han logrado que la Etología desborde su inicial marco descriptivo (Ruwet, 1975).

\section{Lo adquirido: la posición conductista}

Hasta hace unas décadas, la escuela dominante en la explicación del comportamiento (animal y humano) en los EEUU, sobre todo, había sido el conductismo, cuyas figuras más conocidas fueron John B. Watson y Burrhus F. Skinner. Los partidarios de esta corriente sostenían que toda conducta es aprendida; asimismo, creían que los animales nacen como una "página en blanco" sobre la que el ambiente y las experiencias van escribiendo sus mensajes. A través del condicionamiento, se va formando el comportamiento animal. Los conductistas diferenciaban dos tipos de condicionamiento: clásico y operante.

A finales del siglo XIX, el fisiólogo ruso Iván Pávlov descubrió el condicionamiento clásico mientras estudiaba los procesos de la digestión. Comprobó que los perros salivaban automáticamente con el olor de la comida, dando una respuesta incondicionada a un estímulo incondicionado, para usar su terminología. Los conductistas consideraban la salivación como un reflejo simple, semejante al reflejo patalear, que es el movimiento inmediato que realiza la pierna cuando se le da a la rótula un golpecito. Si sonaba una campana en el momento de mostrar la comida al animal, este comenzaba lentamente a asociar este estímulo, en principio irrelevante, con la comida. Al cabo de un cierto tiempo, el sonido exclusivo de la campana, sin mostrar la comida al animal, provocaba la salivación; se había transformado en un estímulo condicionado capaz de producir una respuesta que él denominaba condicionada. El perro había aprendido a asociar cierto elemento con la comida. 


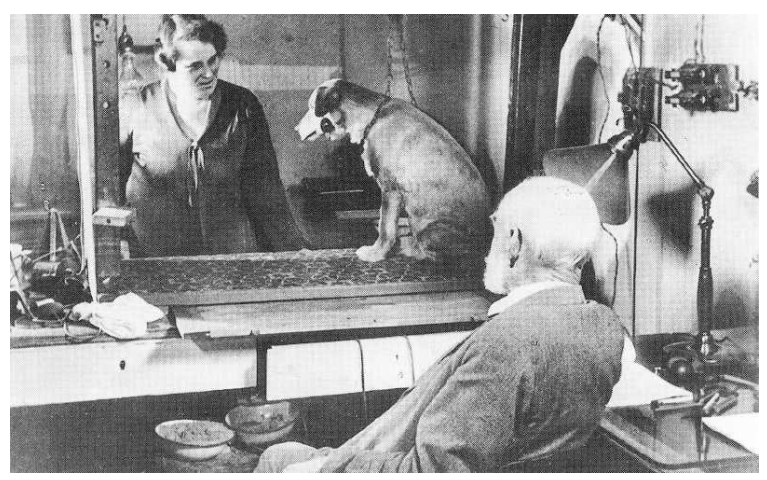

Figura 5: Iván Pavlov en su laboratorio experimentando con su perro, imagen tomada de: http://bio3520.nicerweb.com/Locked/chap/ ch04/4_08-Pavlov.jpg

La segunda categoría, el condicionamiento operante (versión de Skinner del llamado condicionamiento instrumental), trabaja con el principio del refuerzo y el castigo. Una rata, por ejemplo, es adiestrada para pulsar una palanca cuando desea conseguir comida: al principio es premiada por llegar al extremo correcto del laberinto donde se la encierra, después solo cuando se acerca a la palanca, a continuación cuando la pulsa, y así hasta que su conducta se adapta a la tarea. Los conductistas creen que este tipo de aprendizaje, junto al aprendizaje por ensayo-error, combinado con el condicionamiento clásico asociativo de Pavlov, van entrelazando una serie de reflejos y respuestas simples, formando cadenas complejas de respuestas, dependiendo de los estímulos que el medio natural ofrezca. Para los conductistas radicales, por tanto, los animales son capaces de aprender todas las pautas de comportamiento que necesitan

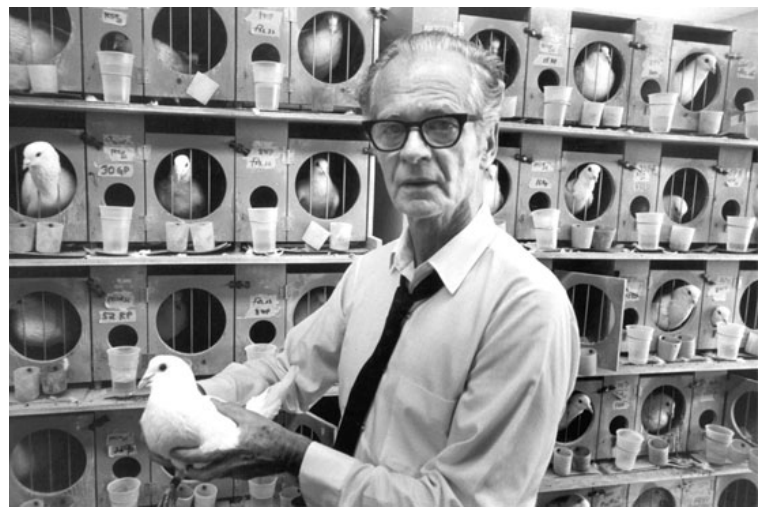

Figura 6: B.F. Skinner en su laboratorio, imagen tomada de: http://www.famouspsychologists.org/ psychologists/b-f-skinner.jpg para adaptarse al medio (a partir de refuerzos positivos, evitando los estímulos aversivos). (Encarta, 1998).

El conductismo radical enfatiza los efectos del ambiente sobre la conducta. Nos dice que la conducta de todos los animales, incluida la de los seres humanos, es el resultado de la evolución (las contingencias de superviviencia y el medio han seleccionado ciertas características biológicas) y del aprendizaje (las contingencias de reforzamiento y el medio seleccionan ciertas características conductuales. La conducta operante permite a nuestra especie rápidamente adaptarse a los cambios de las condiciones ambientales (Tortosa y Civera, 2006).

Skinner es un neoconductista que aportó mucho en el área de la psicología del aprendizaje. Algunos planteamientos básicos de Skinner son: "Las conductas emitidas por el organismo tienen consecuencias y éstas hacen variar la probabilidad de su repetición. Para el aprendizaje de un comportamiento son decisivos los reforzamientos a través de los cuales se obtiene con frecuencia una reacción dada. La conducta se puede analizar con más exactitud si se considera el modo como se relaciona ésta con acontecimientos anteriores y posteriores (Sánchez Carlessi y reyes Romero, 2002).

\section{LO INNATO: EL PAPEL DE LA HERENCIA Y LOS INSTINTOS. EJEMPLOS}

Por el contrario, la Etología, disciplina desarrollada prioritariamente en Europa, sostiene que la conducta animal es innata (instintiva). Una especie de avispa excavadora encuentra y captura solamente abejas de miel. Sin ninguna experiencia previa, la avispa hembra de esta especie excava un complicado túnel hasta encontrar a la abeja, la paraliza con un preciso aguijonazo en el cuello, vuelve a su guarida y, cuando tiene suficientes abejas, pone un huevo en una de ellas y sella la cámara. Según los etólogos, el comportamiento tan especializado de esta avispa está dirigido por una programación dada en sus genes desde el momento de su concepción. Este 
fenómeno se presenta de modo similar en otras especies animales, en las que pueden observarse patrones fijos de acción similares a los de la avispa. En sus posiciones extremas, los defensores de este enfoque sostienen que los comportamientos tardíos en la vida de los animales podrían no ser fruto del aprendizaje, sino de la maduración del individuo, como sucede, por ejemplo, con el vuelo de las aves, que no requiere de ningún aprendizaje, pero que se retrasa hasta que el polluelo tiene fuerza suficiente.

Los tres premios Nobel fundadores de la Etología, el austriaco Konrad Lorenz, el holandés Niko Tinbergen y el alemán Karl von Frisch señalaron cuatro mecanismos básicos (Encarta, 1998) con los que la programación genética ayuda directamente a la supervivencia y adaptación de los animales: los estímulos señal (también llamados estímulo signo, clave, liberador o desencadenante), las pautas fijas de acción (o patrones fijos de conducta), los impulsos y el aprendizaje preprogramado (que incluye la impronta):

\section{Estímulos desencadenantes}

Los estímulos desencadenantes son señales toscas, incompletas, que permiten a los animales reconocer objetos $e$ individuos importantes para su supervivencia cuando se los encuentran por primera vez, sin experiencia previa de aprendizaje con ellos. Las crías de gaviota arenquera, por ejemplo, saben desde el principio a quién dirigir sus llamadas de súplica y sus picoteos para ser alimentadas. Un adulto que vuelve al nido con comida, inclina su pico hacia abajo y lo balancea de forma horizontal frente al polluelo, que a continuación picotea en la mancha roja de la punta, haciendo que su progenitor regurgite la comida. El polluelo reconoce a su progenitor exclusivamente por el estímulo desencadenante de la línea vertical del pico y su mancha roja moviéndose de forma horizontal. Un pico falso de madera puede realizar la misma función que el pico real del progenitor; incluso una aguja de tejer con una mancha roja en la punta puede ser efectiva para conseguir la respuesta de los polluelos (esto se denomina estímulo supranormal).
Los estímulos señal no necesariamente han de ser visuales. La llamada de súplica que un polluelo emite es un desencadenante del instinto de sus progenitores de alimentar a sus crías. El olor peculiar, o feromona, emitido por las hembras de mariposa es un estímulo clave para atraer a los machos.

El uso más general de los estímulos señal dentro del reino animal se da en los comportamientos de comunicación, caza y huida de los depredadores. Los pájaros jóvenes de la mayoría de las especies cazadoras de serpientes, por ejemplo, reconocen y evitan instintivamente a las mortíferas serpientes corales; los patos y gallinas nacen con la capacidad de reconocer y huir de la silueta de los halcones. Estímulos clave semejantes se usan a menudo para recolectar comida. La avispa cazadora de abejas reconoce a las productoras de miel mediante una serie de estímulos desencadenantes, el olor de la abeja atrae a la avispa, la vista de cualquier objeto pequeño y oscuro la conduce al ataque $y$, finalmente, el olor del objeto mientras la avispa prepara su aguijón determina si el ataque se completa o no.

Eluso sucesivo de una serie de desencadenantes aumenta considerablemente la especificidad de lo que eran en principio señales burdas y esquemáticas, estrategia frecuente en la comunicación animal. La mayoría de las especies animales son solitarias, excepto cuando se aparean y cuando crían. Para evitar la confusión, las señales que identifican el sexo y la especie de la pareja potencial de un animal deben ser claras e inequívocas. Por ejemplo, el espinoso, un pequeño pez de agua dulce, usa un sistema de estímulos-signos interconectados para organizar su complejo apareamiento. Cuando llega la época de cría, el costado inferior de los machos se vuelve de un rojo brillante. Este color atrae a las hembras, pero también provoca el ataque de otros machos: los objetos de color rojo brillante de cualquier tipo disparan la agresión del espinoso macho. La hembra responde a esta señal roja con una curiosa postura de aproximación que muestra su vientre hinchado, repleto de huevas. Esto a su vez incita al macho a realizar una danza en zig-zag que conduce a la hembra dentro del 
nido en forma de túnel que él ha construido. La hembra entra en el nido, donde el macho estimula la cola de la hembra con su hocico y lo hace vibrar. La vibración resultante hace que la hembra suelte sus huevas para que el macho las insemine. Si el macho falla en la parte final del ritual, la hembra no depositará sus huevas. Sin embargo, haciendo vibrar a la hembra con un lápiz, aunque ella pueda ver claramente que no es el macho, soltará las huevas. En este caso, el macho, al no haber realizado la última parte del ritual, no las inseminará y se las comerá (Encarta, 1998).

\section{Pautas fijas de acción}

Un segundo descubrimiento importante de los etólogos es que muchos comportamientos complejos son previamente pautas fijas de acción o patrones fijos de conducta, una especie de circuitos completos capaces de dirigir y coordinar los movimientos de diferentes músculos para realizar una tarea determinada. La danza de los espinosos, el aguijonazo de la avispa, o el picoteo de los polluelos de gaviota son pautas fijas de acción.

El primer análisis detallado de un patrón o pauta fija fue la conducta de los gansos de llevar rodando los huevos. Cuando un ganso ve un huevo fuera del nido, lo mira fijamente, estira el cuello hasta que su pico está justo al otro lado del huevo y, suavemente, lo devuelve al nido. A primera vista, esto parecería un comportamiento inteligente, pero en realidad es un patrón mecánico de conducta: casi cualquier objeto suavemente redondeado (es el estímulo señal en este caso), provoca la respuesta. Es más, si se le quita el huevo al ganso una vez que el patrón de respuesta ha comenzado, este sigue estirando su cuello y llevará cuidadosamente un objeto inexistente hasta el nido. Estos actos en vacío han sido objeto de estudio de este enfoque.

Otros tipos de programaciones motoras son aprendidos. En la especie humana caminar, nadar, montar en bicicleta o atarse los zapatos, por ejemplo, comienza aprendiéndose como laboriosos esfuerzos que requieren una atención consciente $y$ total. No obstante, después de un cierto tiempo, estas actividades se automatizan de tal modo que, al igual que las pautas fijas de acción, se realizan de forma inconsciente y sin necesidad de realimentación (feedback). Esta necesidad de realimentación, -que las consecuencias de las acciones motoras sean percibidas, condicionando la conducta posterior-, es universal solo en las etapas iniciales del aprendizaje. Los pájaros cantores al igual que las personas, por ejemplo, deben oírse cuando empiezan a vocalizar, pero una vez que la canción o el habla se dominan, la sordera tiene pocas consecuencias. Las programaciones motoras necesarias se han incorporado al sistema (Encarta, 1998).

\section{Impulso}

El tercer concepto general de la Etología es el del impulso o motivación. Los animales saben cuándo y hacia dónde emigrar, cuándo hacerse la corte o cuándo alimentar a sus crías. En la mayoría de las especies animales tales habilidades son unidades de comportamiento que se activan o desactivan cuando es apropiado hacerlo. Los gansos, por ejemplo, rodarán los huevos solo desde una semana antes de la puesta hasta una semana después de que los polluelos hayan salido del cascarón; fuera de este lapso de tiempo, los huevos no significan nada para ellos.

La conexión o desconexión de estos programas suele implicar complejas relaciones de desencadenantes y temporizadores. En las aves, la preparación de las migraciones en primavera, el dimorfismo sexual (separación de caracteres entre machos y hembras), la defensa territorial y el comportamiento en el periodo de celo se activan por la duración de la luz diurna, que altera los niveles de hormonas en la sangre, provocando cada uno de estos cambios drásticos pero esenciales en su comportamiento.

Un gato, por ejemplo, cazará pequeños animales acechándolos, incluso cuando esté bien alimentado. En ausencia de estímulos, su umbral (el nivel del estímulo requerido para provocar una respuesta) será tan bajo que un gato aburrido acechará, cazará y capturará y presas imaginarias. Esta respuesta injustificada se conoce como 'acto en vacío' (como vimos 
antes con los gansos, es un comportamiento que ocurre en ausencia de un estímulo apropiado) (Encarta, 1998).

\section{Aprendizaje preprogramado}

La cuarta contribución que la Etología ha hecho al estudio del comportamiento animal es el concepto de aprendizaje preprogramado. Los etólogos han mostrado cómo muchos organismos animales están concebidos para aprender habilidades concretas de forma específica en determinados momentos de sus vidas.

\section{- Impronta o troquelado}

Un ejemplo famoso del aprendizaje preprogramado es la impronta. Los ejemplares jóvenes de ciertas especies, los patos por ejemplo, deben seguir a sus padres casi desde que nacen para sobrevivir. Cada patito, incluso si estuviera preparado para reconocer

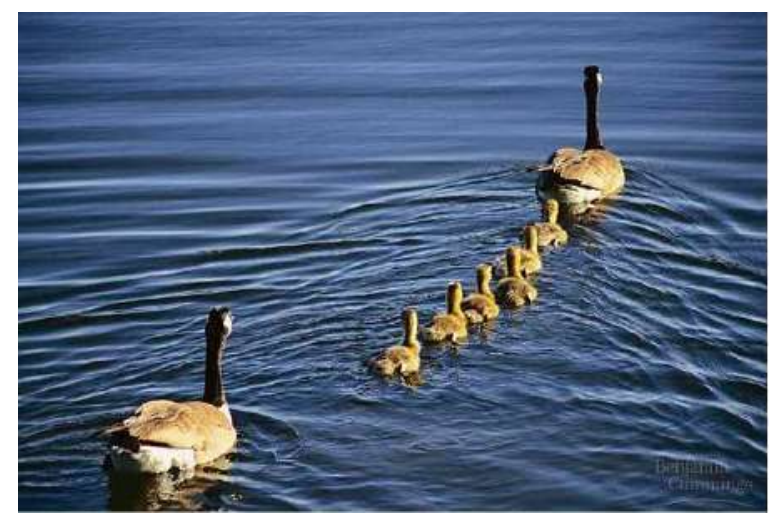

Figura 7: Una madre pato y sus crías. La impronta es evidente y se observa un comportamiento de seguir a la madre. Imagen tomada de: http://2. bp.blogspot.com/-i2IH6pv-e1I/Uql7NwiKgII/ AAAAAAAAADQ/5MyHsjOmQ g/s1600/ taptinhdv7.jpg de forma instintiva a sus congéneres, debería aprender rápidamente a distinguir a sus progenitores de otros adultos. La evolución ha propiciado esta necesidad esencial de memorización, programándolos para que sigan el primer objeto móvil que les produce la llamada específica de su especie. Esta actúa como un estímulo acústico cuya respuesta es el seguimiento.

Sin embargo, es el hecho físico de seguir al progenitor lo que activa el proceso de aprendizaje: los polluelos transportados pasivamente, siguiendo la llamada del padre, no harían la impronta (de hecho, poner obstáculos para que el polluelo tenga que esforzarse para seguir a su progenitor, hace más rápido este proceso). Si se sustituye al pato por un objeto que emite el sonido apropiado y además se mueve, los patitos pueden hacer la impronta con una amplia gama de objetos, incluidas las pelotas de goma, cajas de zapatos y también personas (Encarta, 1998).

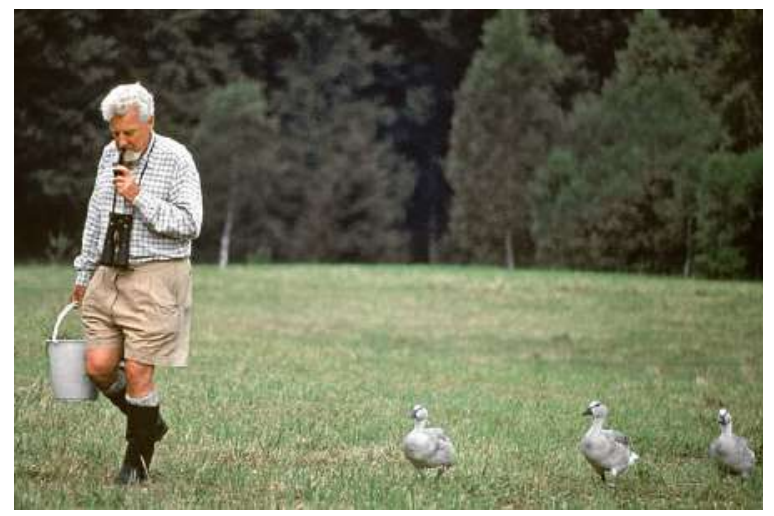

Figura 8: Interesante imagen donde se puede ver a Konrad Lorenz y un grupo de patos que hicieron impronta con él. Imagen tomada de: http:// psiqueyeros.files.wordpress.com/2010/04/konradlorenz-patos.jpg 
Esta fase de impronta paternal suele ser temprana y breve, cesando a las 36 horas del nacimiento. Tiene lugar entonces una nueva fase de impronta que sirve para definir la imagen de la especie que el animal utilizará para seleccionar una pareja apropiada cuando madure. Los etólogos sospechan que la programación genética no especifica muchos detalles visuales, ya que de otro modo una selección ventajosa exigiría que los polluelos nacieran con una imagen predeterminada de su propia especie.

Como el mundo se ha ido poblando de especies distintas, en algunos animales el papel del estímulo señal ha pasado de ser el de identificar la especie animal a la que pertenece, a ser meramente la de dirigir el aprendizaje necesario para distinguir a un congénere de otras criaturas similares. Esta estrategia funciona porque a la temprana edad en que se produce, la mayoría de los animales tienen contacto con muy pocas especies, por lo que la posibilidad de error es mínima en la identificación del sujeto (Encarta, 1998).

Aprovechamos para indicar en esta parte, que en el ser humano, en especial en el bebé, no hay impronta sino apego, que es el nombre dado al primer vínculo afectivo entre el bebé y su madre, decimos la madre porque generalmente es la madre la que se encarga del bebé. De este primer vínculo, los psicólogos han encontrado una muy fuerte experiencia que suele marcar (durante toda la vida inclusive) las relaciones del individuo con los demás y la percepción de sí mismo. De ahí que un buen vínculo temprano con la progenitora suele ser una "vacuna emocional" para los seres humanos. Sobre esto hemos escrito ya en otro momento (Arboccó, 2015b).

\section{- Características del aprendizaje preprogramado}

La impronta, en consecuencia, tiene cuatro características básicas que la diferencian del aprendizaje normal: primero, un periodo de tiempo específico, o periodo crítico, en el que el aprendizaje ha de tener lugar; segundo, un contexto específico, normalmente definido por la presencia de un estímulo señal específico; tercero, una restricción en el aprendizaje para que el animal recuerde solo un estímulo específico, como el olor, e ignore otros que a priori parecerían más relevantes; y cuarto, no hace falta ningún tipo de premio o recompensa (refuerzo positivo en el lenguaje skinneriano), para que el animal aprenda y recuerde lo aprendido (Encarta, 1998).

Estas cualidades son evidentes en muchos tipos de aprendizaje, y hoy somos capaces de comprender el valor que tiene el aprendizaje innato: en un mundo lleno de estímulos, permiten al animal orientarse sobre qué debe saber y qué debe ignorar. Por razones de economía adaptativa, los animales deben recoger solamente el mínimo de información necesaria que les resuelva una situación. Siguiendo con nuestro ejemplo, los patitos de una especie parecen reconocer las voces de sus progenitores, mientras que los de otras se fijan sólo en su aspecto externo. Cuando ingieren veneno, las ratas recuerdan solo el sabor y el olor de la comida envenenada, mientras que la codorniz solo repara en su color. Este fenómeno, conocido como condicionamiento rápido de rechazo, está tan firmemente establecido en muchas especies que una simple exposición a una sustancia tóxica es suficiente para que un animal la rechace toda su vida.

En casi todas las especies hallamos este tipo de predisposición. Los pichones, por ejemplo, aprenden rápidamente a picotear cuando se les premia con comida, pero no a pulsar una palanca (como las ratas) por la misma recompensa. Por otra parte, es casi imposible enseñar a un pájaro a picotear para evitar un peligro, pero aprenden fácilmente a saltar sobre una palanca en esas situaciones. Esas diferencias tienen sentido en el contexto del pasado evolutivo de cada especie: las palomas suelen alcanzar la comida con el pico y no con las patas, y reaccionan al peligro con estas, junto con las alas (Encarta, 1998).

Quizá el mejor ejemplo de un aprendizaje complejo preprogramado sea el del canto de los pájaros. Algunas aves, como las palomas, nacen predispuestas para emitir los arrullos específicos de la especie, y ninguna exposición, por prolongada que sea, a los arrullos de otras 
especies, o la ausencia de ellos, los modificará. Esto mismo ocurre con el repertorio de unas veinte llamadas que casi todos los pájaros usan para comunicar mensajes como el hambre o el peligro.

En los elaborados cantos de las aves cantoras, sin embargo, suele influir el aprendizaje. Un pájaro en soledad, por ejemplo, trina de forma muy pobre en comparación con lo que haría en estado salvaje. El canto de los pájaros muestra todas las características del aprendizaje por impronta o troquelado; normalmente hay un periodo crítico donde aprenden lo más básico: los cantos de su especie, cantos seleccionados de entre el mundo de sonidos que les rodea: Un gorrión de cabeza blanca, obligado a escuchar los cantos de otras especies, indefectiblemente percibirá solo el de la suya y lo grabará en su memoria. Esta capacidad de reconocimiento del canto específico se basa en un estímuloseñal acústico.

A pesar de las limitaciones obvias, el aprendizaje del canto permite un rango de variaciones considerable: cualquier trino funcionará mientras cumpla unas características esenciales. Precisamente por ello, porque la memorización no es perfecta y admite cierta flexibilidad, los cantos de muchos pájaros han desarrollado variantes regionales, a modo de dialectos, que sirven para una especie de comportamiento social.

Una prueba algo más llamativa de preprogramación del aprendizaje social en los pájaros es la transmisión de conocimientos sobre sus depredadores. La mayoría de los pájaros están sometidos a dos tipos de peligros: pueden ser atacados directamente por aves de presa o sus indefensos polluelos pueden ser devorados por depredadores de nidos. Cuando los pájaros vislumbran un ave de presa acostumbran a emitir una señal de alarma específica, a modo de silbido, que indica la necesidad de esconderse. Otra llamada, continuada y tumultuosa, indica, por otra parte, la presencia de predadores de los nidos, incitando a los demás pájaros que anidan en las proximidades a hostigar al potencial depredador hasta obligarlo a alejarse. Ambas señales son estímulos clave (Encarta, 1998).
Los pájaros nacen sin conocer apenas las especies que son peligrosas; lo aprenden observando el objeto de las llamadas que oyen. Los enemigos son categorizados como tales de un modo tan automático que a los pájaros enjaulados se les puede engañar, haciéndoles reaccionar ante la presencia de una botella de leche si oyen una llamada de alarma mientras se les muestra la botella (conducta que después transmitirán de generación en generación). Esta variante de la impronta parece ser el mecanismo por el que muchos mamíferos (primates incluidos) obtienen y transmiten información social de vital importancia sobre la presencia de alimentos y de peligros.

\section{- Pautas de comportamiento complejos}

La evolución, actuando sobre los cuatro mecanismos estudiados por los etólogos, ha generado una serie casi interminable de comportamientos asombrosos con los que los animales parecen estar perfectamente adaptados a su entorno. Ejemplos destacados son los sistemas de navegación, comunicación y organización social de las abejas, que se sirven principalmente del Sol como referencia para la navegación, memorizando la dirección de su vuelo con respecto al Sol y tomando en cuenta los vientos que pueden afectar a su dirección. El Sol es una referencia difícil para la navegación por su movimiento aparente de Este a Oeste, pero las abejas nacen con la capacidad de compensar ese movimiento. Cuando una nube tapa el Sol, las abejas utilizan sus pautas para orientarse por la luz ultravioleta polarizada que determina su posición. Cuando el cielo está muy nublado, que ni siquiera llega la luz ultravioleta polarizada, las abejas conectan automáticamente un tercer mecanismo de navegación: un "mapa mental" de las marcas situadas en los alrededores de sus nidos (Encarta, 1998).

El estudio del sistema de navegación de las abejas ha revelado muchos aspectos de los mecanismos empleados por los animales superiores. Hoy día se sabe que las palomas mensajeras, por ejemplo, usan el Sol como brújula; son capaces de compensar su movimiento aparente, de percibir la luz ultravioleta y la polarizada $y$, en los días 
nublados, utilizan una brújula secundaria de naturaleza magnética. Las palomas superan a las abejas en este último aspecto así como en la disposición de un mapa interno. Con estos sistemas, una paloma separada de su palomar por cientos de kilómetros y en la más absoluta oscuridad, volverá casi directamente a su hogar cuando la soltemos.

Las abejas productoras de miel también muestran excelentes capacidades comunicativas: una exploradora que busca alimento, ejecutará una danza en planos verticales al panal al volver de una expedición productiva. La danza indica a las demás abejas la distancia y dirección del alimento, describiendo una serie de "ochos", en cuya parte central -donde se cruzan los dos bucles del "8" - la abeja hace vibrar su cuerpo. El ángulo de esta parte del recorrido indica la dirección del alimento: si apunta hacia arriba, está en la dirección del Sol, mientras que si está, por ejemplo, $70^{\circ}$ a la izquierda de la vertical, queda a $70^{\circ}$ a la izquierda del Sol (Encarta, 1998). La cantidad de 8 que realiza indican la distancia que separa al enjambre del alimento.

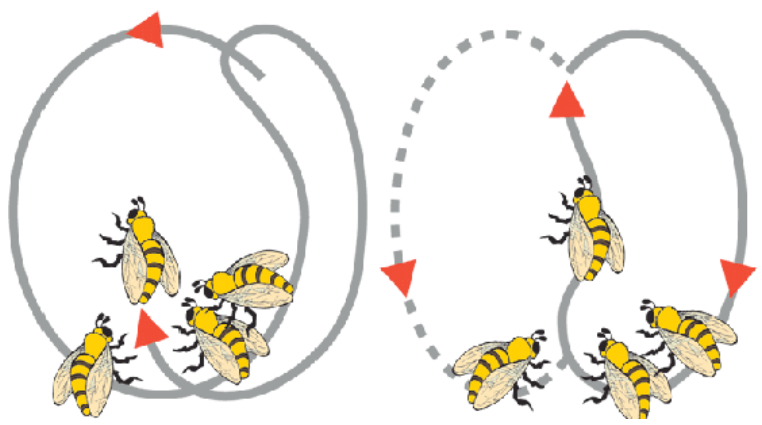

Figura 9: La "danza de las abejas" descubiertas por Karl von Frisch. Imagen tomada de: http://3.bp.blogspot.com/Zv_sHIY1OIY/T5mluQktOvI/AAAAAAAACOQ/ uuDÜgvVxhpU/s1600/La-danza-de-las-abejas.png

La complejidad de este lenguaje "bailado" (Von Frisch, 2007) ha preparado el camino para el estudio de los animales superiores. Hoy se conocen algunas especies que se comunican a través de una serie de señales específicas. Los monos vervet, por ejemplo, tienen un repertorio común de gestos y sonidos para expresar sus estados de ánimo y necesidades sociales, pero usan además un vocabulario específico para referirse a los depredadores: una llamada específica alerta al grupo de que hay depredadores aéreos; otra advierte de depredadores de cuatro patas, como los leopardos; otra de las serpientes, y otra más de la presencia de otros primates. Cada tipo de alarma provoca una reacción diferente: los leopardos trepan a las ramas más altas de los árboles, mientras que los predadores aéreos caen en los árboles. Las señales que emiten pueden ser innatas, pero más adelante los jóvenes aprenden por observación cuáles son las especies más peligrosas que deben temer. Una cría de estos monos puede dar la alarma aérea ante un buitre, una cigüeña, o incluso una hoja que cae, pero con el paso del tiempo, ignorará todo lo que no sea el águila marcial.

\section{- La cuestión del altruismo animal}

Un aspecto fascinante de algunas sociedades animales es la forma desinteresada que, al parecer, tienen de favorecer a otros de su misma especie. En un enjambre las obreras trabajan incesantemente en la colmena durante tres semanas, después de las cuales salen al exterior a buscar comida otras dos o tres semanas hasta que se agotan.

El altruismo es, de hecho, un sistema de ayuda mutua, desinteresada, pero en las especies animales no se da de forma gratuita. Un chimpancé espulgará a otro en las zonas donde este no alcance a llegar, pero más tarde se intercambiarán los papeles. Este sistema, sin embargo, requiere que los animales sean capaces de reconocer su especie y, por tanto, de rechazar a aquellos que no "reconocen" su ayuda.

El comportamiento del urogallo macho, que se congrega en vistosos grupos, es un ejemplo de este tipo de altruismo. Las hembras se unen a esos grupos para aparearse, pero solo unos pocos machos situados en el centro del grupo engendrarán la siguiente generación. Docenas de otros machos anuncian con vehemencia sus virtudes, pero solo logran atraer más hembras hacia el centro del grupo. Sin embargo, la selección natural no se equivoca, los machos 
van avanzando hacia el interior año tras año, hasta que llegan a ser elegidos (Encarta, 1998).

El altruismo de las abejas tiene una explicación completamente genética. Las obreras son hembras estériles, por lo que, al no poder transmitir sus genes a otras generaciones favorecen un comportamiento altruista: se dedican a proteger la colonia, recolectar alimento, alimentar a la reina y a los zánganos y cuidar de las crías. Este sistema, conocido como selección por parentesco, supone que un animal ejecuta una tarea de escasa utilidad (o incluso negativa) para su supervivencia como individuo, pero muy positiva para sus parientes (en definitiva, para sus mismos genes). Los leones macho que se unen para derrocar a otro macho que procede de otra manada, y así perpetuar su parentesco, suelen ser hermanos (de la misma generación), mientras que las leonas del territorio que cazan en grupo y comparten la comida son un complejo entramado de hermanas, hijas y tías (de varias generaciones).

$\mathrm{Ni}$ siquiera las sociedades humanas son ajenas a la selección por parentesco. Los antropólogos, en sus estudios de sociobiología, han demostrado que la organización social de las sociedades preindustriales estaba basada en el parentesco. Estas observaciones, combinadas con el reciente descubrimiento de que el aprendizaje del lenguaje humano es en parte una suerte de impronta (por ejemplo, las consonantes son reconocidas de manera innata como estímulos señal), sugieren que la conducta humana está muy relacionada con la conducta animal, más de lo que nos imaginamos (Encarta, 1998).

\section{EL CARÁCTER ADAPTATIVO DEL COMPORTAMIENTO ANIMAL}

Debemos a la escuela de Nikolaas Tinbergen los siguientes hechos verificados, según nos cuenta Jean Claude Ruwet en su texto Etología (1975). Es sabido que algunas especies de orugas adoptan sobre las ramas una posición retorcida que las hace pasar por ramillas. Se ha podido probar que este comportamiento es adaptativo, y les permite escapar a los pájaros insectívoros. A este efecto, se ha procedido a la fabricación de una serie de orugas cuya posición evocaba a unas ramillas, y de otra serie cuya posición era la común. Y se ha comprobado que la predación de los pájaros se ejercía mucho sobre las segundas.

En una colonia de gaviotas densamente poblada, todas las hembras ponen casi por las mismas fechas el primer huevo. Esta simultaneidad, asegurada por los ritmos fisiológicos y por la sincronización mutua de las parejas, es adaptativa. Reduce los riesgos de destrucción de los huevos. Ha podido ser verificada mediante la simple colocación de huevos artificiales en los nidos, en fechas precoces o tardías. La mayoría de tales huevos, en efecto, son robados o destruidos por otras aves. El hecho resulta ventajoso, por cuanto las diferentes parejas de la colonia llegadas al mismo estadio del ciclo de reproducción aseguran una defensa común de los huevos y polluelos contra los intrusos. En el supuesto de que una gaviota presentara una modificación en el ritmo hipofisiario inductora de una postura precoz, apenas tendría posibilidad de transmitir ese carácter a sus descendientes, dada la eliminación de sus huevos a cargo de los depredadores (Ruwet, 1975).

Un tercer ejemplo demuestra que un comportamiento puede ser el resultado de un compromiso entre varias presiones selectivas. Después del nacimiento de las crías, la gaviota reidora elimina los fragmentos de las cáscaras: los coge con el pico y los arrojas lejos de la colonia. Sin embargo, espera aproximadamente dos horas antes de efectuar esta limpieza del nido.

Exactamente el tiempo necesario para que el plumón ${ }^{2}$ del pequeñín se seque. Ahora bien, se ha podido comprobar que los corvidos localizan sobre todo los nidos que contienen restos de cáscaras. Pero se ha demostrado también que un polluelo recientemente salido del huevo y cuyo plumón esté húmedo es atacado por las gaviotas vecinas. El transporte de las cáscaras fuera del nido dos horas

\footnotetext{
Pluma muy delgada, semejante a la seda, que tienen las aves debajo del plumaje exterior. (RAE, 2014)
} 
después del nacimiento de las crías tiene en cuenta estos dos peligros. Inmediatamente después de la salida de los polluelos de los huevos, es muy grande el riesgo de predación intraespecífica. En cambio, dos horas más tarde, es ya muy inferior el riesgo de llamar la atención de las cornejas (Ruwet, 1975). Así, pues, el conjunto del comportamiento de supresión de las cáscaras es la resultante de la intervención de varias fuerzas selectivas.

La acción de tales fuerzas es constante en todas partes, y resulta particularmente evidente al nivel de los adornos y paradas nupciales: estos adornos tienen por efecto atraer sobre el animal, dispuesto a la parada, la atención de los rivales o de las hembras, pero atraen asimismo, indefectiblemente, la mirada de eventuales predadores. En periodo de reproducción, la especie juzga ventajoso el despliegue de esos adornos y paradas nupciales, aun a riesgo de llamar la atención del predador. Pero tiene también interés en limitar en el tiempo esas exhibiciones de movimientos y coloridos vistosos. En el caso de los pájaros vivamente coloreados y de acusado dimorfismo sexual, se consigue esto mediante la exigencia de mudas pre y posnupciales. En los peces, se alcanza el mismo resultado mediante la acción de los cromátoforos, que hacen sumamente lábiles las pautas de coloración, así un pez cíclico pasa sin transición, de un aspecto vistoso a una coloración críptica, según se halle en presencia de una hembra o sobrevenga un peligro ${ }^{3}$.

Puede decirse casi siempre que un comportamiento es adaptado. Un determinado comportamiento, que parece aberrante en una animal cautivo, se explica y cobra todo su significado cuando se le observa en su entorno natural. Hay comportamientos que parecen enteramente aberrante e ilógicos. Aun cuando, en su expresión, puedan antojársenos inadaptados, sabemos, sin embargo, que resultan de mecanismos subyacentes que sí están adaptados. Para el animal, en efecto, es importante la descarga de sus excedentes de motivación, la eliminación de los influjos que no pueden manifestarse por su vía normal, la disminución de sus estados de tensión. Asimismo, la organización jerarquizada de los instintos (Tinbergen, 1953) tiene por efecto, mediante la canalización de los influjos hacia una vía de espera -el comportamiento apetitivo- o hacia los centros de nivel inferior, permitir el paso progresivo de comportamientos muy genéricos a comportamientos de creciente especificidad, y obliga al animal a aplazar el acto de consumación hasta el momento en que este se halla perfectamente adaptado a la situación estimulante. El mecanismo, en sí mismo, es adaptativo. Por consiguiente, cuando se desea determinar en que medida está adaptado un comportamiento, es necesario no solo estudiar el animal en toda su integridad, sino también lograr una comprensión global de la situación, tanto fisiológica como ecológica (Ruwet, 1975).

\section{Lo innato y lo adquirido}

Los animales heredan estructuras comportamentales. Dichas estructuras están ajustadas al medio y al modo de vida propios de la especie. El ajuste se lleva a cabo progresivamente de generación en generación, por efecto de las presiones que seleccionan entre los individuos, a aquellos cuyo equipamiento comportamental está mejor adaptado al entorno (Ruwet, 1975). Esa adaptación al nivel de la especie se plasma en una evolución de los comportamientos a lo largo de la historia de la especie. Existe, de otro lado, un proceso de adaptación que tiene lugar al nivel del individuo y se traduce por cambios en el transcurso de la historia de dicho individuo; este, en efecto, puede complicar y modificar su comportamiento en función de circunstancias particulares, y tener en cuenta ulteriormente la experiencia adquirida ${ }^{4}$.

Así, pues, el animal puede estar adaptado al medio por haber recibido de una sola vez

Este punto es interesante, recordemos cuando los seres humanos también "pasamos" de un color a otro en presencia de una emoción intensa como el miedo, la cólera o la vergüenza.

4 Por ejemplo, no es igual el comportamiento de un perro salvaje (hijo y nieto de perros salvajes viviendo todos en su hábitat natural) que el comportamiento de un perro domesticado descendiente de perros igualmente domesticados y criados en un hábitat humano. 
un equipamiento comportamental adecuado. $Y$ puede asimismo adaptarse al medio por haber organizado progresivamente su comportamiento en función de las condiciones que se encuentra. La importancia relativa de los dos procesos varía según las conductas y según las especies consideradas. Está claro que un artrópodo, cuya duración normal de vida se limita a veces a unas pocas semanas, que no conoce a sus padres $y$ crece sin ambiente familiar, debe poseer un equipamiento pronto a funcionar inmediatamente de modo adecuado. Pero, por el contrario, es menos necesario en el caso de los animales criados en el seno de un grupo familiar, cuyo desarrollo es más lento y más alta la media de vida, ya que tienen ocasión de ajustar y perfeccionar su comportamiento en el transcurso de su educación y maduración (Ruwet, 1975).

Puede afirmarse, siguiendo a Ruwet, como regla general, que, en grados diversos, el comportamiento final de un individuo es el resultado de una complementariedad entre las conductas heredadas, fijadas por la misma razón que los atributos físicos y las conductas aprendidas, adaptadas a las circunstancias. Esta complementariedad queda magníficamente ilustrada por la progresiva complicación del comportamiento en el polluelo de la gaviota reidora (Tinbergen, 1965). El polluelo empieza por romper su cascarón con la uña que posee en el extremo de la mandíbula superior. Es esta una acción sumamente importante que solo realiza una vez en su vida, y que ejecuta sin más del modo adecuado. Muy pronto, incluso antes de quedar seco, da picotazos en el pico del adulto. Empieza a tomar y a ingerir alimento. En el transcurso del primer día se sostiene sobre sus patas, da sus primeros pasos, arregla su plumón. $\mathrm{Si}$ el adulto lanza un grito de alarma, se agazapa. Más adelante, a los 2 o 3 días, reacciona a ese mismo grito huyendo antes de agazaparse. Más tarde, huye, se oculta, y se agazapa. Pasado más tiempo, huye, se oculta en un lugar elegido y conocido, y se agazapa. A los 7 días, el polluelo hace sus primeros movimientos de vuelo. A las dos semanas, llama a sus compañeros. A las tres semanas, se alimenta por su cuenta: picotea primero diferentes objetos, $y$, luego, se orienta selectivamente hacia lo que es comestible. A las cinco semanas, hace sus primeros ejercicios de vuelo. Se posa torpemente y rueda por el suelo cuando aterriza. Pero muy pronto aprende a posarse con el viento de cara. Para beber, se dirige hacia toda superficie brillante; aprende luego a reconocer la superficie del agua.

Empieza por practicar en el suelo todos los movimientos de baño, y aprende después a ejecutarlos en el agua. Algunos movimientos son ya perfectos desde el principio. Otros se van perfeccionando progresivamente. Algunos se ejecutan desde el primer momento. Otros, en cambio, no parecen al principio tener un objeto; luego se adaptan a las circunstancias, se ajustan a las situaciones.

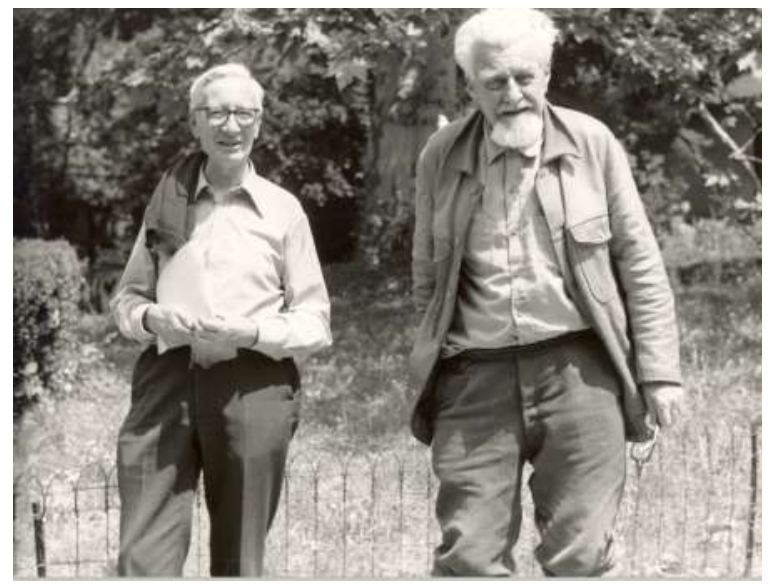

Figura 10: Tinbergen y Lorenz, imagen tomada de: http://www.perros.com/content/perros_com/ imagenes/editor/Lorenz_and_Tinbergen1.jpg

Durante generaciones, los investigadores han discutido para determinar lo que en un comportamiento es innato o adquirido. De hecho, la distinción resulta a veces muy difícil, dando lugar a confusiones que solo es posible evitar mediante el estudio del desarrollo de los comportamientos de una animal desde su nacimiento, tanto en condiciones naturales como en condiciones experimentales. En efecto, porque un comportamiento sea estereotipado $e$ idéntico en diferentes individuos, no vamos a calificarlo como innato, ya que en unas circunstancias idénticas y en un medio idéntico, comos suele ser el caso, tendrán la tendencia a aprender las mismas cosas y a 
expresarlas del mismo modo. E inversamente, el hecho de que un comportamiento no sea ejecutado desde el principio de una forma perfecta y definitiva no autoriza a concluir que dicho comportamiento no sea innato. La complementariedad existente entre lo innato y lo adquirido es constante y dinámica (Ruwet, 1975).

El comportamiento heredado se asienta progresivamente. Algunas respuestas se traducen muy pronto en la vida, como la reacción de fuga ante los predadores y los movimientos de comodidad y de cuidados corporales. Otras no hacen su aparición hasta mucho más tarde, cuando el individuo se hace adulto, en particular, todos los comportamientos vinculados a la reproducción como el combate territorial en el caso de un animal vertebrado. Este progresivo asentamiento se combina con la aparición de los procesos de aprendizaje, y hasta se da la circunstancia de que ciertas manifestaciones aprendidas aparecen antes de haber concluido la maduración completa del comportamiento innato. Además, no se dada solamente un desarrollo paralelo de los procesos de aprendizajes $y$ del comportamiento innato, sino que existe entre ambos una estrecha dependencia. Los genes expresan únicamente potencialidades y estas se manifiestan en función de las condiciones del medio. De la misma forma, lo que un animal puede aprender viene limitado por sus informaciones genéticas, está predeterminado por su equipamiento innato. Los animales, al igual que el ser humano, heredan simplemente predisposiciones para aprender determinadas cosas en determinados momentos.

Así, pues, el comportamiento final de un animal (y esto aplica también para el animal humano) está en función de las informaciones genéticas $y$ de las informaciones del medio o entorno. Y el desarrollo de dicho comportamiento, tanto en lo que atañe a lo innato como en lo que se refiere a lo adquirido, está en función, primordialmente, de la evolución y asentamiento del material de equipo subyacente: arquitectura esquelética, muscular, nerviosa; mecanismos filológicos; adquisición y afinamiento de las percepciones sensoriales, etc. (Ruwet, 1975).

\section{La herencia y el aprendizaje van de la mano}

Los comportamientos, en su forma final, son el resultado de interacciones entre elementos heredados y un proceso de aprendizaje. Los hay muy simples y evidentes. Así, pongamos por caso, para abrir una avellana, la ardilla utiliza tres secuencias heredadas: manipular, roer, abrir. La ardilla joven sabe hacer desde el principio las tres operaciones, pero debe aprender a combinarlas convenientemente. Hastapasado un tiempo, no consigue manipular la avellana de modo que pueda roerla en el punto de más débil resistencia y provocar así una rotura neta y rápida de la cáscara. Los restos de avellanas rotas por ardillas de corta edad dan fe de las arduas tentativas realizadas al principio. Existe asimismo ejemplos muy complejos, como es el canto de algunos pájaros: ruiseñor, alondra, pinzón, zarcero. El canto de estos pájaros esta compuesto de motivos heredados, comunes a todos los individuos, y de elementos aprendidos por imitación, tomados de la propia especie o de otras especies. Así, por ejemplo, el canto del carricero políglota, o del alcaudón, constituye un autentico popurrí en el que cabe encontrar los motivos típicos de todas las especies que frecuentan el mismo hábitat (Ruwet, 1975).

Si consideramos las observaciones de Jean Claude Ruwet, (hasta los años sesenta), el canto de los pájaros, pese a haber sido objeto de una abundante literatura especializada, constituía uno de los aspectos del comportamiento animal que menos se prestaba a un estudio objetivo y a una experimentación. En efecto, lo único que podía hacerse era imaginar diferentes modos de anotación musical muy ingeniosos, pero siempre incompletos y subjetivos. Los recientes progresos de la electrónica han posibilitado ya, a este nivel, la realización de notables trabajos.

Marler y Tamura (1964) han descubierto diferentes dialectos regionales en el gorrión americano de cabeza blanca. Las crías originarias de las diferentes regiones, criadas en el aislamiento, presentan un canto de base siempre idéntico, común a todas. Se trata de una pauta motora heredada, característica 
de la especie. Los dialectos regionales se constituyen por aprendizaje. Este tiene lugar en el transcurso de los tres primeros meses de vida del gorrión, por consiguiente, antes de que él mismo haya podido cantar alguna vez, puesto que el canto no hace su aparición hasta la primavera siguiente, cuando el gorrión delimite un territorio de nidificación.

Un pequeñuelo macho, capturado en su primer otoño, o sea, después de los tres meses en que es posible el aprendizaje, y mantenido luego en el aislamiento, canta en primavera, y desde el primer momento, según el dialecto perfecto de la región de origen. Así, pues, hasta la edad de tres meses, es posible enseñar cualquier dialecto a cualquier gorrión, sobre la base siempre del canto heredado, transmitiéndole las grabaciones guardadas al efecto. Ahora bien, si el pequeñuelo es mantenido en el aislamiento durante sus tres primeros meses de vida y solo durante su cuarto mes se le facilita la audición de las grabaciones, la experiencia no surtirá efecto alguno, porque habrá ya concluido el periodo de aprendizaje. ${ }^{5}$

Este individuo conocerá únicamente el canto de base heredado. Tanto en un caso como en otro, el resultado de las experiencias no puede juzgarse hasta la primavera siguiente.

Konishi (1985) ha llevado más lejos aún el análisis. Provocó la sordera a unos gorriones de cabeza blanca y de edades diferentes, mediante la extracción de un huesecillo del oído interno. Estos pájaros no podían oír ya ni los sonidos que ellos mismos producían ni los de su entorno. En el caso del gorrioncillo precozmente sometido a la operación, se obtiene en la primavera siguiente una sucesión de sonidos inconexos en los que no cabe ya identificar el canto de base. De donde se deduce que el gorrión de corta edad debe oírse a sí mismo para poder emitir el canto heredado. En el caso de la operación practicada después de que el gorrión, en su periodo de aprendizaje, haya oído un canto completo y normal, pero antes de que el mismo haya cantado todavía, se produce de nuevo la incapacidad de emitir otra cosa que no sea un canto compuesto de sonidos inconexos. De donde se desprende que el gorrión debe oírse a si mismo para conformar lo que él produce a aquello que es heredado y a aquello que es aprendido.

En el caso, en fin, de la operación efectuada en un individuo en su segundo año de vida, tras haber cantado ya correctamente por lo menos una vez, la operación en cuestión no tiene ya efecto alguno. El canto es hilvanado y reconocible (canto de base, si el individuo fue aislado durante el periodo de aprendizaje; canto completo y perfecto, si se trata de un individuo educado).

El estudio del canto de los pájaros constituye el ejemplo más completo que mejor ilustra la complementariedad y las sutiles interacciones existentes entre la herencia y el aprendizaje.

Por regla general, se considera que las diferencias de comportamiento son un criterio de localización y delimitación del aprendizaje, mientras que la identidad de comportamiento por parte de diversos individuos es un signo que avala lo innato. Ciertamente, dado que el aprendizaje depende de la experiencia individual, cabe esperar que individuos diferentes, emplazados en condiciones diferentes, no aprendan exactamente lo mismo. Y así es en el laboratorio. Pero, en la naturaleza, los individuos de la misma especie, que viven inmersos en unas condiciones idénticas y en un hábitat idéntico, tienen todas las probabilidades de aprender lo mismo. El ruiseñor aprende el canto de la especie al contacto con sus progenitores. Si no hubiese sido criado en el aislamiento o en contacto con otras especies, no habría sido posible percatarse de que su canto incluye una parte de aprendizaje. Para determinar exactamente lo que un animal aprende efectivamente y aquello que hereda, hay que criar, pues, a ese animal bajo diferentes condiciones, y comparar los resultados obtenidos con el comportamiento

Período crítico o periodo sensible es aquél espacio de tiempo en el que el organismo es mucho más influenciable por la estimulación que recibe pudiendo por tanto aprender algo o desarrollar una habilidad particular. También se emplea el concepto para explicar comportamientos humanos. 
normal. La crianza en el aislamiento deja aflorar el comportamiento heredado. Pero, puesto que las potencialidades genéticas se expresan en función de las condiciones ambientales, se tiene asimismo interés en diversificar las condiciones de crianza, para poder determinar cuales son los factores que influyen sobre el desarrollo y expresión de los comportamientos, y en qué medida; así como cuales son los retrasos, las desviaciones, las carencias o modificaciones (Ruwet, 1975).

\section{CONCLUSIONES}

1. La Etología es una ciencia que combina el trabajo de campo (observación de los animales en su medio natural) con el análisis de la conducta (ya sea mediante experimentos de laboratorio). Se considera fundadores de esta ciencia a Karl Von Frisch, Konrad Lorenz y Nikolaas Tinbergen, recibiendo los tres en 1973 el premio Nobel como reconocimiento a su importante contribución a esta rama de la Zoología.

2. Karl von Frisch (1886-1982) se especializó en el estudio de las abejas, analizando los modos de comunicación de estos insectos mediante danzas de forma $\mathrm{y}$ ritmo variables, conocido esto como el llamado "lenguaje de las abejas". Averiguó asimismo que poseen la capacidad de distinguir los colores.

3. Konrad Lorenz (1903-1989) fue el primero en describir el fenómeno de la impregnación o acuñación (impronta) y llevó a cabo estudios sobre el instinto en los gansos, estableciendo las bases de la Etología comparada (Lorenz, 1986).

4. Nikolaas Tinbergen (1907-1988) estudió el comportamiento de los animales en su medio natural, contribuyendo a la creación de la llamada Etologia positiva. Centró sus trabajos en los instintos.

5. Los comportamientos animales se han estudiado desde dos perspectivas bastante diferentes, o bien los animales aprenden todo lo que hacen (enfoque conductista o behaviorista), o bien saben instintivamente como hacerlo (enfoque etológico).

6. Las reacciones del tipo prueba por ensayo $y$ error han desempeñado, desde hace mucho tiempo, un importante papel en los experimentos de laboratorio sobre la capacidad de aprendizaje de los animales. Actúan, por ejemplo, en la orientación de ratas y otros animales en laberintos. En un laberinto de prueba, el animal deberá aprender a hallar el camino hacia una meta donde recibe una recompensa, comúnmente en forma de alimento.

7. Una condición básica para todo aprendizaje es que el animal se encuentre en un estado de motivación tal que alguno de sus mecanismos desencadenantes innatos sea activado o lo será en el momento del aprendizaje. Un pez deberá estar hambriento para poder aprender a reaccionar a nuevos estímulos relacionados con la toma de alimento, y un ave puede aprender a utilizar un cierto tipo de ramas para la construcción del nido solo cuando su comportamiento de reproducción y el acto inherente a la construcción del nido han sido activados por efecto hormonal. Muchas observaciones indican que el aprendizaje se realiza más fácilmente cuanto más fuerte es la motivación (activación), algo parecido a lo que ocurre en los seres humanos. Entre nosotros, es una experiencia diaria que aprendemos con mayor facilidad lo que nos interesa en el momento.

8. Se puede decir que la impronta es un proceso asociativo de aprendizaje que influye sobre el desencadenamiento de ciertos actos instintivos tempranos, que está limitado a un periodo de tiempo relativamente corto en el desarrollo del joven animal y que lleva a producir asociaciones bastante estables. En el caso de los seres humanos, no hay impronta pero sí apego, primer vínculo afectivo entre el recién nacido y su madre de cuyo resultado se obtendrá una personas con carencias socioemocionales (en caso de ser defectuoso) o con habilidades 
interpersonales y una buena autoestima (en caso ser positivo y seguro).

9. Se considera que las diferencias de comportamientos son un criterio de localización y delimitación del aprendizaje, mientras que las semejanzas de comportamientos por parte de diversos organismos es un signo que avala lo innato. Ciertamente, dado que el aprendizaje depende de la experiencia individual, cabe esperar que individuos diferentes, emplazados en condiciones diferentes, no aprendan exactamente lo mismo. Y así es en el laboratorio. Pero, en la naturaleza, los individuos de la misma especie, que viven inmersos en unas condiciones idénticas y en un hábitat idéntico, tienen todas las probabilidades de aprender lo mismo.

10. El animal básicamente actúa motivado por la necesidad de su alimentación, de su reproducción y de su supervivencia, al no tener mayor conciencia de sí mismo ni de su especie solamente se motiva por las tres causas mencionadas. Esto no niega que algunos animales superiores presenten aspectos como emociones primarias $y$ formas de apego que los lleva a actuar acercándose y defendiendo a sus amos, a su pareja, a sus crías y de pronto a miembros de su especie.

11. En las especies animales, la lucha por la existencia permite que los miembros de una especie que sean los más fuertes sobrevivan, en tanto que los más débiles perezcan, lo que traería como consecuencia que la especie se consolide con la permanencia de los más fuertes, y esto ocasionaría el fortalecimiento de la especie en cuestión.

12. Finamente el estudio de los animales exige un respeto a su integridad ecológica, una preocupación por tener en cuenta sus necesidades y exigencias para poder eventualmente no interferir negativamente en sus ambientes y sus conductas, así como elaborar planes de contingencia para el daño ya realizado a las distintas especies y a sus hábitats. 


\section{REFERENCIAS}

Arboccó de los Heros, M. (2015a) La cuestión del altruismo en los animales. Diario Oficial El Peruano. 12, 9 de enero del 2015

Arboccó de los Heros, M. (2015b) Bowlby, las madres y la teoría del apego. Diario Oficial El Peruano. 10, 9 de julio del 2015

Denegri, M. A. (2012) Normalidad y anormalidad y El asesino desorganizado. Lima: Fondo Editorial de la Universidad Inca Garcilaso de la Vega.

Encarta (1998) Conducta animal. Enciclopedia Microsoft Encarta. Microsoft Corporation.

Fabricius, E. (1971) La conducta de los animales. Buenos Aires: editorial Universitaria de Buenos Aires.

Konishi, M (1985) Birdsong: from behavior to neuron. Annual Reviews. Neurosci, 8: 125-170, California Institute of Technology.

León, R. (2010) La literatura psicológica del siglo XX. Lima: Editorial de la Universidad Ricardo Palma.

Lorenz, K. (1986) Fundamentos de Etología. Buenos Aires: Editorial Paidós.

Marler, P.; Tamura, M. (Dec, 11, 1964) Culturally Transmitted Patterns of Vocal Behavior in Sparrows. Science, New Series, Vol. 146, No. 3650. 1483-1486.

Nisbett, A. (1986) Lorenz. Barcelona: Salvat Editores.

Real Academia de la Lengua Española (2014) Diccionario de la Lengua Española. Vigésima tercera edición, España.

Ruwet, J.C. (1975) Etología, Biología del comportamiento. Barcelona: Editorial Herder.

Sánchez Carlessi, H. y Reyes Romero, C. (2002) Diccionario biográfico de Psicología Contemporánea. Lima: Editorial de la Universidad Ricardo Palma.

Skinner, B.F. (1938) The Behavior of Organisms. Nueva York: Appleton Century Crofts.

Skinner, B.F. (1953) Ciencia y comportamiento humano, Nueva York, McMillan Comp.

Tinbergen, N. (1953) Social behaviour in animals, with special reference to vertebrates. Methuen. 150 págs. Londres.

Tinbergen, N. (1965): Animal behavior. Nueva York. Time Inc.

Tortosa, F. y Civera, C. (2006) Historia de la Psicología. España: Editorial Mc Graw Hill.

Von Frisch, K. (2007) El señor de las abejas. México: Editorial Pax. Disponible en: https://books. google.com.pe/books?id=06RtQSB2xe8C\&pg =PA2\&lpg $=\mathrm{PA} 2 \& \mathrm{dq}=\mathrm{La}+\mathrm{vida}+\mathrm{de}+\mathrm{las}+\mathrm{abe}$ jas $+\% 281957 \% 29+$ karl + von + frisch $\&$ source $=$ bl\&ots $=11$ zNRhUrft $\&$ sig $=$ pAliMiG5tGiUifyZS 
13iPJF4mL4\&hl=es\&sa $=\mathrm{X} \& e \mathrm{i}=\mathrm{CdvCVI29E8ikNqS \_ g5AG \& ved=0CCoQ6AEwAw \# v=onep}$ age\&q $=$ La\%20vida\%20de\%20las\%20abejas\%20(1957)\%20karl\%20von\%20frisch\&f $=$ false, recuperado el 23 de enero del 2015.

\section{Imágenes extraídas de la web:}

Figura 1: Konrad Lorenz, imagen tomada de http://www.nndb.com/people/757/000091484/ konrad-lorenz-1-sized.jpg

Figura 2: Graciosa toma de Lorenz, imagen extraída de: http://www.famouspsychologists.org/ psychologists/konrad-lorenz.jpg

Figura 3: Nikolaas Tinbergen. Imagen tomada de: http://www.oxforddnb.com/images/articleimgs/40/40022_1_300px.jpg

Figura 4: Karl von Frisch. Imagen tomada de: http:/www.ecured.cu/images/b/b0/Karl Von_Frisch.jpg

Figura 5: Iván Pavlov en su laboratorio experimentando con su perro, imagen tomada de: http:// bio3520.nicerweb.com/Locked/chap/ch04/4_08-Pavlov.jpg

Figura 6: B.F. Skinner en su laboratorio, imagen tomada de: http://www.famouspsychologists.org/ psychologists/b-f-skinner.jpg

Figura 7: Una madre pato y sus crías. La impronta es evidente y se observa un comportamiento de seguir a la madre. Imagen tomada de: http://2.bp.blogspot.com/-i2IH6pv-e1I/Uql7NwiKgII/ AAAAAAAAADQ/5MyHsjOmQ_g/s1600/taptinhdv7.jpg

Figura 8: Interesante imagen donde se puede ver a Konrad Lorenz y un grupo de patos que hicieron impronta con él. Imagen tomada de: http://psiqueyeros.files.wordpress.com/2010/04/ konrad-lorenz-patos.jpg

Figura 9: La "danza de las abejas" descubiertas por Karl von Frisch.

Imagen tomada de: http://3.bp.blogspot.com/-Zv_sHIY1OIY/T5mIuQktOvI/AAAAAAAACOQ/ uuDUgvVxhpU/s1600/La-danza-de-las-abejas.png

Figura 10: Tinbergen y Lorenz, imagen tomada de: http://www.perros.com/content/perros_com/ imagenes/editor/Lorenz_and_Tinbergen1.jpg

Fecha de recepción: 12 de junio 2015

Fecha de aceptación: 23 de julio 2015 